\title{
Pancytopenia in pregnant patients with COVID-19 infection and vitamin B12 deficiency: a case report study
}

\author{
Neha Agarwal, Neha Khatri, Preeti Singh
}

\begin{abstract}
Background: Folate and vitamin B 12 deficiency can lead to pancytopenia in pregnancy. Some cases of pancytopenia due to COVID-19 infection have also been reported. The two cases that we present are related to the coincidence of pregnancy and deficiency of folic acid and vitamin B12 with COVID-19 infection.

Case presentation: A 26-year- woman G3P1L1A1 and 21-year-woman G2P1L1 presented with pancytopenia and mild COVID-19 infection. The antenatal period was uneventful, and both cases also had folate and vitamin B12 deficiency. They received blood products, folic acid, and vitamin B12 supplementation. COVID- 19 infection was managed well with analgesic and vital monitoring. Postpartum hemorrhage occurred in the second case, which was well managed with uterotonics. All laboratory parameters came out to be normal after three months of supplementation of folic acid and vitamin B12.

Conclusion: Pancytopenia in pregnancy due to folate and vitamin B12 deficiency and COVID- 19 infection can be easily managed with timely intensive targeted therapy, but we should be extra vigilant while handling such complicated cases, keeping in mind all possible differential diagnoses for pancytopenia.
\end{abstract}

Keywords: Pancytopenia, COVID- 19, Folate, Vitamin B12, Pregnancy, Megaloblastic Anemia, India

\section{Background}

Pancytopenia in pregnancy is a rare manifestation characterized by a concurrent reduction in all blood cell lines leading to anemia, leukopenia, and thrombocytopenia. Vitamin B 12 and folate deficiency generally presents as megaloblastic anemia, but its infrequent presentation as pancytopenia has also been reported [1]. The prevalence of vitamin B12 and folate deficiency in pregnancy is significantly high in developing countries due to poor socioeconomic and nutritional status [2]. Hemodilution and transplacental transfer of vitamin B 12 contribute to physiological fall in vitamin B 12 levels [2]. In addition to Vitamin B12 deficiency, pancytopenia is a rare manifestation of certain viral infections, including novel COVID- 19 infection [3]. This report presents two pregnant patients who had Covid-19 infection with concurrent Vitamin B12 and folate deficiency and presented with pancytopenia.

*Correspondence: nehakhatri3112@gmail.com

*Department of Obstetrics and Gynaecology, Maulana Azad Medical College, New Delhi, India.

Full list of author information is available at the end of the article

\section{Case Report}

Case I

A 26-year-woman G3P1L1A1 presented to the emergency room of Maulana Azad Medical College, Delhi, on 16th July 2020 at 36 weeks and five days of gestation with complaints of fever, generalized body weakness, and pedal edema for one week. RTPCR analysis of nasopharyngeal swab was positive for SARS-CoV-2. There was no history of breathlessness, chest pain, palpitations, blood in stools, or urine. There was no history of rashes, mucosal bleeding, or numbness in hands and feet. She was vegetarian and took iron supplements containing $60 \mathrm{mg}$ elemental iron regularly in this pregnancy. She was not on any drugs, which may lead to myelosuppression. There was no complication in the previous pregnancy; however, the examination revealed subconjunctival pallor and bilateral pedal edema. Her uterus was relaxed and 34-36 weeks in size. Complete blood count with red cell indices shown in Table 1. Her serum vitamin B12 was 139 pmol/L, and serum folate was $2.43 \mathrm{ng} / \mathrm{ml}$. Peripheral blood smear showed normocytic normochromic RBCs with some macrocytes, spherocytes, and few microcytes. 
Table 1 Complete blood count (CBC) with red cell indices at the time of admission

\begin{tabular}{|c|c|c|c|c|c|c|c|c|}
\hline \multirow{2}{*}{$\begin{array}{l}\mathrm{CBC} \text { at the time } \\
\text { of admission }\end{array}$} & $\mathrm{Hb}$ (in gm \%) & Hct $(\%)$ & $\operatorname{MCV}(\mathrm{Fl})$ & $\mathrm{MCH}(\mathrm{Pg})$ & MCHC (g/dl) & RDW (\%) & $\operatorname{TLC}(/ \mathrm{L})$ & Platelets (/L) \\
\hline & 5.9 & 16.3 & 107 & 35 & 33 & 22 & $0.32 \times 10^{9}$ & $39 \times 10^{9}$ \\
\hline
\end{tabular}

Total leukocyte count and platelet count were reduced on smear, but no atypical cells or giant platelets were seen, and there was no evidence of hemolysis. Prothrombin time was 11.1 $\mathrm{sec}$, and the international normalized ratio was 0.98. Liver function and renal function tests were normal. Plasma lactate dehydrogenase was $214 \mathrm{IU} / \mathrm{L}$, and serum uric acid level was 7.1 $\mathrm{mg} / \mathrm{dl}$. Ultrasound whole abdomen was normal. Bone marrow biopsy was deferred as the patient was not willing for any invasive procedure. She received two units packed cell volume and four-unit platelets. Maternal and fetal well-being was monitored. Vitamin B 12 and folate were given as intravenous infusion for seven days. She was given symptomatic treatment for COVID-19 infection, such as antipyretics for fever and pain, adequate nutrition, and hydration. Four weeks after admission, she went into spontaneous labor and delivered a healthy male baby of 2900 grams with APGAR of 9,9,9 at 40 weeks and five days of the period of gestation. There was no postpartum hemorrhage or any other postnatal complication. She was discharged on a postnatal day 5 with hemoglobin of $7.9 \mathrm{~g} / \mathrm{dl}$, total leukocyte count of $0.50 \times 109 / \mathrm{L}$, and platelet count of 52 x109/L on oral methyl cobalamin and folic acid. Table 2 . Showing her investigations after three months of therapy.

Table 2 Complete blood count with red cell indices, vitamin B12, and folate levels after three months

\begin{tabular}{|l|l|l|l|l|l|l|l|l|l|}
\hline $\begin{array}{l}\text { Hb (in } \\
\text { gm \%) }\end{array}$ & Hct $(\%)$ & MCV $(\mathrm{Fl})$ & MCH $(\mathrm{Pg})$ & $\begin{array}{l}\text { MCHC } \\
(\mathrm{g} / \mathrm{dl})\end{array}$ & RDW $(\%)$ & TLC $(/ \mathrm{L})$ & Platelets $(/ \mathrm{L})$ & $\begin{array}{l}\text { Vitamin } \\
\mathrm{B} 12(\mathrm{pg} / \mathrm{ml})\end{array}$ & \begin{tabular}{l} 
Serum Folate \\
\hline 12.4
\end{tabular} \\
\hline
\end{tabular}

\section{Case II}

A 21-year-old gravida 2 para 1 was admitted in the labor room of Maulana Azad Medical College, Delhi, on 24th November 2020 at 39 weeks of gestation given asymptomatic Covid positive status by Reverse transcription-polymerase chain reaction (RT-PCR) with severe anemia and extreme fatigue. She looked pale, with no other abnormalities detected in her physical examination. Her uterus was 32 weeks in size, and her estimated fetal weight was below the fifth centile on the growth chart. She did not have any chest pain, palpitations, shortness of breath, abdominal pain, or numbness. There was no history of heavy menstrual bleeding, blood in stool or urine. There was no history of previous blood transfusions, and she was also a vegetarian. She took her iron supplements containing $60 \mathrm{mg}$ elemental iron regularly during this pregnancy. Her previous childbirth was a normal vaginal delivery in the hospital with no other complications. Her investigations are listed in Table 3.

Table 3 Complete blood count (CBC) with red cell indices at the time of admission

\begin{tabular}{|c|c|c|c|c|c|c|c|c|c|}
\hline \multirow{2}{*}{$\begin{array}{l}\mathrm{CBC} \text { at the } \\
\text { time of } \\
\text { admission }\end{array}$} & $\begin{array}{l}\mathrm{Hb} \text { (in } \mathrm{gm} \\
\% \text { ) }\end{array}$ & Hct (\%) & $\mathrm{MCV}(\mathrm{Fl})$ & $\mathrm{MCH}(\mathrm{Pg})$ & $\begin{array}{l}\text { MCHC } \\
(\mathrm{g} / \mathrm{dl})\end{array}$ & RDW (\%) & TLC (/L) & Platelets (/L) & $\mathrm{Hb}$ (in gm \%) \\
\hline & 5.2 & 16.6 & 103 & 36 & 32 & 23 & $0.22 \times 109$ & $15 \times 109$ & 5.2 \\
\hline
\end{tabular}

Her serum Vitamin B12 was 143 pmol/L. Plasma serum folate was $2 \mathrm{ng} / \mathrm{mL}$, and serum ferritin was $68 \mathrm{ng} / \mathrm{mL}$. Peripheral blood smear showed dimorphic anemia with moderate anispoikilocytosis with pancytopenia (Figure 1). Plasma lactate dehydrogenase (LDH) was high (2295 U/L), but liver function and renal function test and serum uric acid were normal. Prothrombin time and INR were normal. Ultrasound of the whole abdomen showed no hepatosplenomegaly. The expected fetal weight was less than 10th centile on the antenatal scan, but the doppler was normal. She has given three units PCV and four units platelets. Intravenous vitamin B12 and folate were given

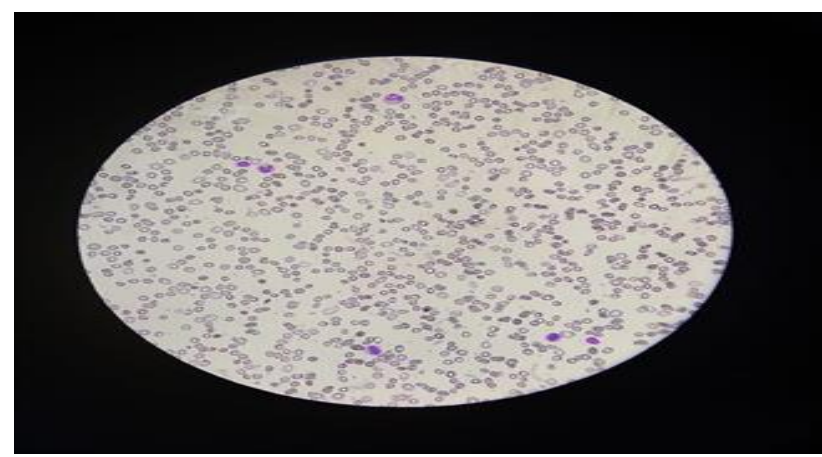

for seven days. She did not develop any symptoms of covid- 19, so only vital monitoring was done. After one week of admission, she went into spontaneous labor and delivered a healthy baby girl of 2290 gm with APGAR of 9,9,9. She had an atonic postpartum hemorrhage, which was controlled with uterotonics. Prophylactic balloon tamponade with condom catheter was done, and it was kept for 24 hours. She was discharged on oral hematinic, methyl cobalamin, and folic acid. Both patients responded well to oral hematinic, methyl cobalamin, and folic acid. Maternal and neonatal outcomes were also satisfactory.

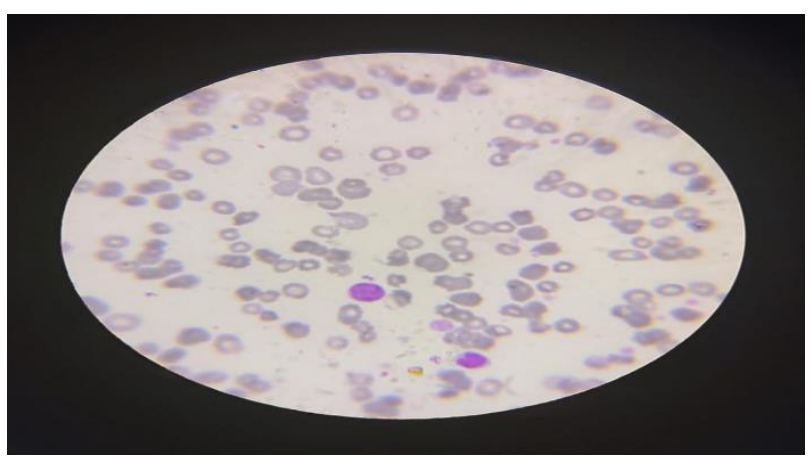

Figure $1 \mathrm{a}(100 \mathrm{X})$ and Figure $1 \mathrm{~b}(40 \mathrm{X})$ are the microscopic picture of peripheral blood smear of the first case showing pancytopenia with marked anispoikilocytosis, macrocytes, and a few macro ovalocytes. 
Table 4 Complete blood count, vitamin B12, and folate levels after three months of follow-up.

\begin{tabular}{|l|l|l|l|l|l|l|l|l|l|}
\hline $\begin{array}{l}\mathrm{Hb} \text { (in gm } \\
\%)\end{array}$ & Het (\%) & MCV (Fl) & MCH (Pg) & MCHC (g/dl) & RDW (\%) & TLC (/L) & Platelets (/L) & $\begin{array}{l}\text { vitamin } \\
(\mathrm{pg} / \mathrm{ml})\end{array}$ & $\begin{array}{l}\text { serum folate } \\
(\mathrm{ng} / \mathrm{ml})\end{array}$ \\
\hline 11.4 & 34.9 & 86 & 28 & 34 & 15 & $1.18 \times 10^{9}$ & $141 \times 10^{9}$ & 299 & 4.06 \\
\hline
\end{tabular}

\section{Discussion}

Pancytopenia in pregnancy is caused by nutritional deficiency, hypersplenism, aplastic anemia, leukemia, viral infections like Epstein Barr virus (EBV), human immunodeficiency virus (HIV), and other novel emerging infections. It can be a lifethreatening condition in pregnancy as it may lead to obstetric hemorrhage, cardiac failure, and sepsis [4].

Lymphopenia is a common laboratory finding in COVID-19 infected patients, and it usually correlates with disease severity; however, pancytopenia is a relatively rarer manifestation of COVID-19 infection. Most cases of SARS-Cov-2 induced pancytopenia are reported in immunocompromised patients [5,6,7]. Issa et al. [5] reported persistent pancytopenia in an immunocompromised patient who had severe COVID-19 infection with cytokine storm. Bone marrow aspirate was also positive for SARS-CoV-2. Hershby et al. [6] reported a similar patient with covid induced pancytopenia, but he had a milder clinical course, and bone marrow aspirate was negative for COVID- 19 virus Pancytopenia also resolved as soon as symptoms of COVID-19 subsided. Ufuk et al. [7] reported a "rare case" of pancytopenia and typhlitis (neutropenic enterocolitis) in a diabetic old age female case of COVID-19. Bridwell et al. [8] presented a case of covid induced pancytopenia in an immunocompetent patient with no known risk factors, who eventually developed multiple organ failure [8]. Hematological manifestations of COVID- 19 infection and their clinical outcomes seem highly unpredictable.

Our patients were pregnant with a milder clinical course of COVID-19 infection compared to the cases mentioned above. Pregnancy is known to cause immunosuppression. In addition, they had mild vitamin B 12 and folate deficiency.

Likewise to our two cases, Pawlak et al. [9] reported that strict vegetarians are at greater risk of developing vitamin B12 deficiency. Moreover, COVID-19 infection leads to the elevation of proinflammatory cytokines such as interferons and tumor necrosis factor-alpha (TNF- $\alpha$ ), which may depress the hematopoietic stem cells. In addition, when antigenic epitopes situated on myelocytes are exposed to the virus, it leads to the production of autoantibodies, resulting in the destruction of all cell lines [8]. The preexisting nutritional deficiencies in both our patients along with new covid infection may explain the myelosuppression leading to pancytopenia. Le Gouez et al. [10] reported three pregnant women with mild COVID- 19 infection and thrombocytopenia. One of them had postpartum hemorrhage (PPH), although none of them required intensive care. Idris and Arsyad [2] reported a case of vitamin B12 deficiency presented as pancytopenia in pregnancy who responded to parenteral cyanocobalamin and had good perinatal outcomes. Compared to our cases, this patient had normal folate levels, extremely low vitamin B12 levels, and no other viral infection leading to pancytopenia. There is no evidence of stillbirth, fetal growth restriction, or miscarriage among pregnant women with COVID-19 infection, although it is associated with an increased likelihood of iatrogenic preterm birth [11]. Our patients were infected with mild covid and went into spontaneous labor at term. The risk of vertical transmission to neonates remains unclear. Alzamora et al. [12] reported possible vertical transmission in one pregnant woman with severe COVID-19 infection. In our cases, nasopharyngeal swabs of neonates on day 2 were negative for SARS-CoV-2. To the best of our knowledge, this is the first case report of successful management of pancytopenia in vitamin B12 and folate-deficient pregnant women with COVID- 19 infections (Figure 1c).

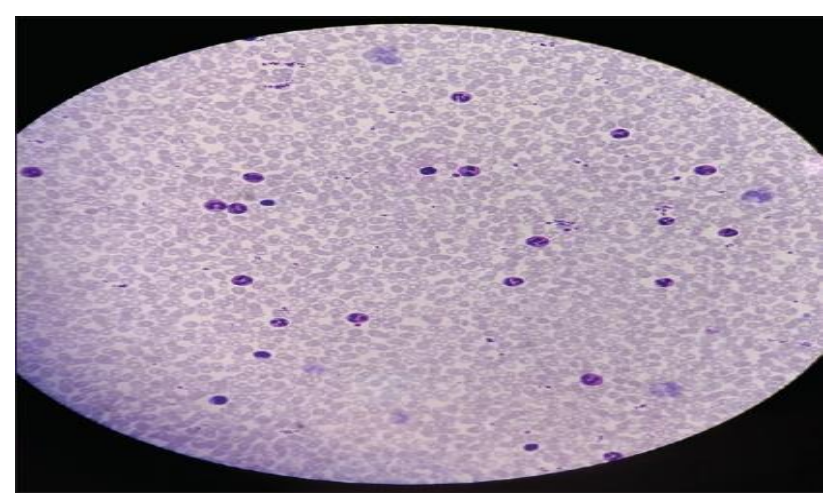

Figure $1 \mathrm{c}$ shows normocytic normochromic peripheral blood smear after three months of oral folate and vitamin B 12 supplementation of the first case.

It was challenging to decide whether pancytopenia was due to vitamin B12 deficiency or due to COVID-19 infection. It is also possible that COVID-19 infection might have aggravated pancytopenia due to B12 and folate deficiency. Our case report emphasizes the importance of screening for vitamin B 12 and folate deficiency and using a multidisciplinary and definite approach while handling such complicated cases.

\section{Conclusion}

Pancytopenia in pregnancy due to folate and vitamin B12 deficiency is a reversible cause. It can be easily managed with early diagnosis and prompt treatment. Delay in diagnosing folate and vitamin B12 deficiency can lead to serious maternal and neonatal outcomes. Folic acid should be given to all pregnant women prophylactically

Vitamin B12 supplementation should be given to strict vegetarians. COVID-19 infection is a self-limiting infection and requires symptomatic management, but we should be extra vigilant while handling such complicated cases and keeping in mind all possible differential diagnoses for pancytopenia.

\section{Abbreviation}

RTPCR: reverse transcriptase-polymerase chain reaction; INR: International Normalized Ratio; TLC: Total Leukocyte Count; $\mathrm{Hb}$ : Hemoglobin, Hct: Hematocrit, MCV: mean corpuscular volume, MCH: mean corpuscular hemoglobin, MCHC: mean corpuscular hemoglobin concentration, RDW: Red cell distribution width 


\section{Declaration}

Acknowledgment

We would like to thank all the participants for their responses and insight during the COVID-19 pandemic.

\section{Funding}

The authors received no financial support for their research, authorship, and/or publication of this article.

Availability of data and materials

Data will be available by emailing nehakhatri3112@gmail.com.

Authors' contributions

Authors' contributions - All authors participated equally in fulfilling this paper. All have read and approved the final manuscript.

Ethics approval and consent to participate

We conducted the research following the Declaration of Helsinki. Ethical permission was granted by Institutional Review Board at Maulana Azad Medical College, Delhi, 2021. Participant consent form was secured.

Consent for publication

Not applicable

Competing interest

The authors declare that they have no competing interests.

\section{Open Access}

This article is distributed under the terms of the Creative Commons Attribution 4.0 International License (http://creativecommons.org/licenses/by/4.0/), which permits unrestricted use, distribution, and reproduction in any medium, provided you give appropriate credit to the original author(s) and the source, provide a link to the Creative Commons license, and indicate if changes were made. The Creative Commons Public Domain Dedication waiver (http://creativecommons.org/publicdomain/zero/1.0/) applies to the data made available in this article, unless otherwise stated.

\section{Author details}

${ }^{1}$ Department of Obstetrics and Gynaecology, Maulana Azad Medical College, New Delhi, India

\section{Article Info}

Received: 21 June 2021

Accepted: 16 July 2021

Published: 21 July 2021

\section{References}

1. Sal E, Yenicesu İ, Eroltekin Z, Kaya Z, Kocak U, et al. Hemolysis and pancytopenia related vitamin b12 deficiency: a case report. J Hematol Transfus 2016;4(1): 1043.

2. Idris N, Arsyad A. Vitamin B12 deficiency presenting as pancytopenia in pregnancy: a case report. Malays Fam Physician. 2012 Aug 31;7(2-3):46-50

3. Martín Pozuelo Ruiz de Pascual R, López Pardo P, LópezDóriga Bonnardeaux P. Pancytopenia during SARS-CoV-2 infection. Medicina Clínica (English Edition). 2020;155(8):364-365.

https://doi.org/10.1016/j.medcli.2020.06.016

4. Rajput Y, Wankhede UN. A rare case report: pregnancy with pancytopenia. Int $\mathrm{J}$ Reprod Contracept Obstet Gynecol 2017; 6:5633-5. DOI: http://dx.doi.org/10.18203/2320-1770.ijrcog20175296

5. Issa N, Lacassin F, Camou F. First case of persistent pancytopenia associated with SARS-CoV-2 bone marrow infiltration in an immunocompromised patient. Ann Oncol 2020;31(10):1418e1419.

doi: 10.1016/j.annonc.2020.06.016

6. Hersby DS, Do TH, Gang AO, Nielsen TH. COVID-19associated pancytopenia can be self-limiting and does not necessarily warrant bone marrow biopsy for the purposes of SARS-CoV-2 diagnostics. Ann Oncol.2021;32(1):121123. https://doi.org/10.1016/j. annonc.2020.09.020.

7. Ufuk F, Bulgurcu E, Sari T. COVID-19-associated pancytopenia and typhlitis. Am J Emerg Med. $2021 \mathrm{Jul}$; 45:685.e1-685.e3. doi: 10.1016/j.ajem.2020.12.049.

8. Bridwell RE, Inman BL, Birdsong S, Goss S, Long B. A coronavirus disease-2019 induced pancytopenia: A case report. Am J Emerg Med. 2021 Feb 24:S07356757(21)00151-0. doi: 10.1016/j.ajem.2021.02.043. Epub ahead of print. PMID: 33653644; PMCID: PMC7902224.

9. Pawlak R, Lester SE, Babatunde T. The prevalence of cobalamin deficiency among vegetarians assessed by serum vitamin B12: a review of the literature. Eur J Clin Nutr. 2014 May;68(5):541-8. doi: 10.1038/ejcn.2014.46. Epub 2014 Mar 26. Erratum in: Eur J Clin Nutr. 2016 Jul;70(7):866

10. Le Gouez A, Vivanti AJ, Benhamou D, Desconclois C, Mercier FJ. Thrombocytopenia in pregnant patients with mild COVID-19. Int J Obstet Anesth. 2020 Nov; 44:13-15. doi: 10.1016/j.ijoa.2020.05.010.

11. Coronavirus (COVID-19) Infection in Pregnancy [Internet]. 2nd ed. Royal college of obstetricians and gynecologists; $2020 . \quad$ Available from: https://www.rcog.org.uk/globalassets/documents/guideline s/2020-10-14-coronavirus-covid-19-infection-inpregnancy-v12.pdf [Accessed on 20th January 2021].

12. Alzamora MC, Paredes T, Caceres D, Webb CM, Valdez LM, La Rosa M. Severe COVID-19 during Pregnancy and Possible Vertical Transmission. Am J Perinatol. 2020 Jun;37(8):861-865. doi: 10.1055/s-0040-1710050. 